Provided for non-commercial research and education use. Not for reproduction, distribution or commercial use.

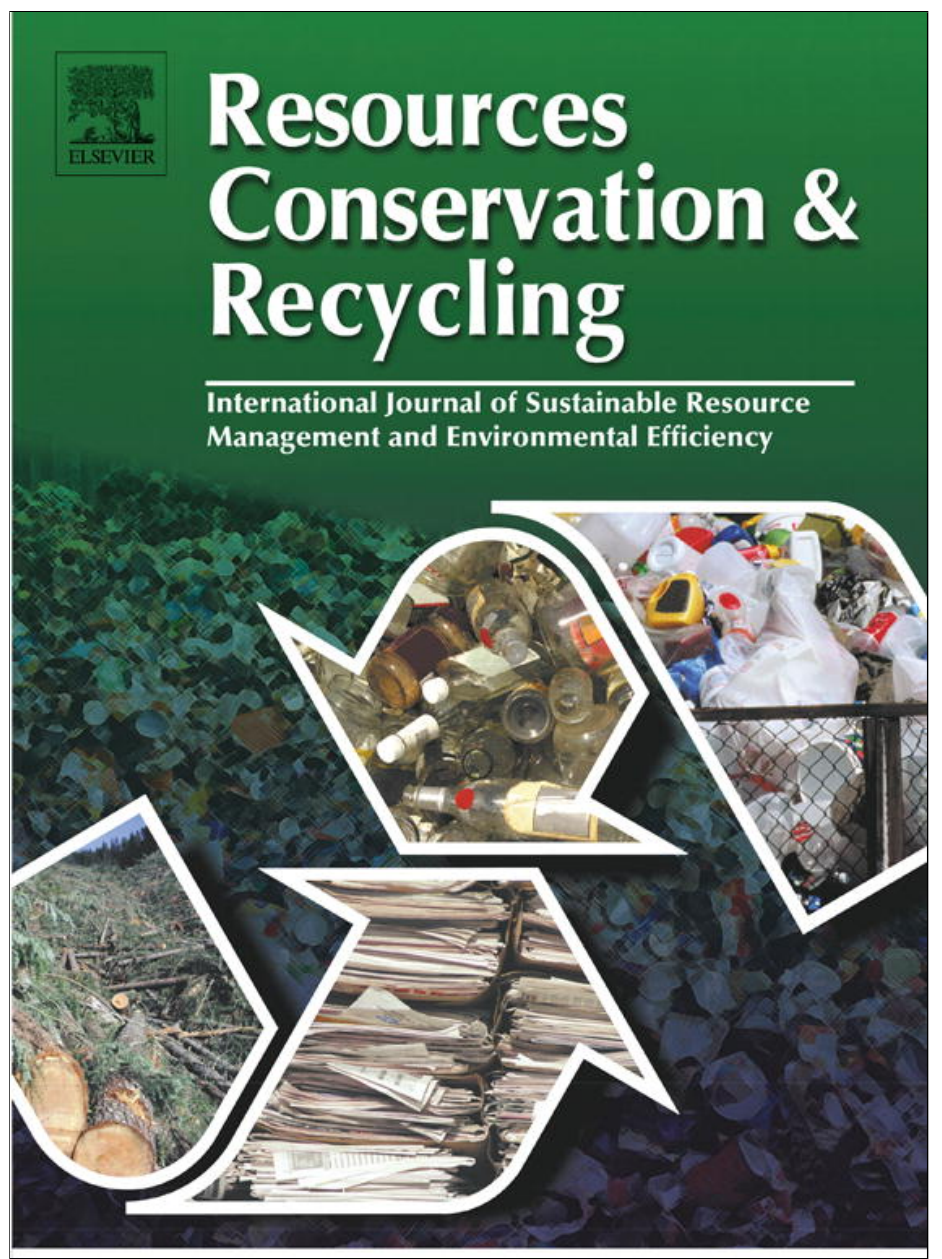

This article appeared in a journal published by Elsevier. The attached copy is furnished to the author for internal non-commercial research and education use, including for instruction at the authors institution and sharing with colleagues.

Other uses, including reproduction and distribution, or selling or licensing copies, or posting to personal, institutional or third party websites are prohibited.

In most cases authors are permitted to post their version of the article (e.g. in Word or Tex form) to their personal website or institutional repository. Authors requiring further information regarding Elsevier's archiving and manuscript policies are encouraged to visit: 


\title{
Moving up the waste hierarchy: Car boot sales, reuse exchange and the challenges of consumer culture to waste prevention
}

\author{
Nicky Gregson*, Mike Crang, Jennifer Laws, Tamlynn Fleetwood, Helen Holmes \\ Department of Geography, Durham University, Science Site, South Road, Durham, DH1 3LE, UK
}

\section{A R T I C L E I N F O}

Article history:

Received 5 March 2013

Received in revised form 11 June 2013

Accepted 13 June 2013

\section{Key words:}

Waste prevention

Reuse

Reuse exchange

Consumer culture

Car boot sales

\begin{abstract}
A B S T R A C T
Moving up the waste hierarchy is a key priority for UK waste policy. Waste prevention requires policy interventions to promote reuse. The term 'reuse exchange' has been adopted by UK policy makers to describe a variety of second-hand trading outlets including car boot sales, charity shops and online exchange sites. As waste policy is based on tonnage diverted from disposal (or landfill), policy interventions to promote reuse exchange will be based on the weight of goods estimated to be flowing through these sites. This paper uses a combination of field survey data and scale-up estimation to quantify and characterise the weight of goods exchanged at car boot sales in England in 2012. This is estimated at 50-60 000 tonnes per annum. The paper emphasises that movement up the waste hierarchy brings waste policy into closer contact with household consumption practices. It draws on qualitative research to show that, for participants, car boot sales are not associated with waste prevention. Instead, car boot sales rely on stocks of surplus household goods and exemplify the culture of thrift, which enables more, not less, consumption. The paper shows the collision between the social values that inform thrift and the environmental values that underpin reuse; and it argues that the policy goal of enhanced recovery for reuse might best be achieved by working with consumer culture. Two ways of achieving this are suggested: interventions that make it easier for consumers to do the right thing, through promoting opportunities for the circulation of stocks of surplus goods, for example, through increasing the frequency of car boot sales; and interventions which recognise that car boot sales also generate waste, which could be recovered for reuse.
\end{abstract}

() 2013 Elsevier B.V. All rights reserved.

\section{Introduction}

The waste hierarchy comprises a set of options for attending to waste, preferentially ranked in terms of their perceived environmental benefit. Disposal (effectively landfill) and recovery (as energy) are at the bottom of the hierarchy; recycling, or materials recovery, is in the middle; and (preparation for) reuse, or reduction, and prevention at the apex. The EU Waste Framework Directive requires that policy interventions by member states be increasingly targeted higher up the hierarchy, whilst recognising that moving up the hierarchy is mediated by both technical efficiencies and economics. To move up the hierarchy will involve not just the comparison between different potential future actions but also their comparison with more established interventions. Potential measures aimed at waste prevention will therefore be compared to existing and projected performance in relation to recycling and energy recovery from waste. Against this backdrop, the Government Review of Waste Policy in England 2011 highlights the

\footnotetext{
* Corresponding author. Tel.: +440191334 4683.

E-mail address: nicky.gregson@durham.ac.uk (N. Gregson).
}

importance of developing a range of measures to encourage waste prevention and reduction, notably through encouraging reuse, and signals forthcoming policy formulation via the development of a comprehensive Waste Prevention Programme (Defra, 2011, p 6).

Waste prevention through reuse is often identified with ideas of stewardship, conservation and preservation (Lane and Watson, 2012). It is intimately linked in policy discourse to fostering a culture of sustainable consumption that is seen as the antithesis of current modes of consumption, which are characterised in terms of 'the throwaway society' (Defra, 2011 c.f. Gregson et al., 2007a; O'Brien, 2008; Evans, 2012). At its simplest reuse is often understood through the invocation to hold onto and care about our things, by repairing them and/or finding new uses for them. It relates to the stewardship of what is already in our care, and is often connected to previous historical periods, notably war time, characterised by austerity and associated with phrases such as 'Waste not Want not' (Cooper, 2008; Strasser, 2000). The sense is both that history can teach more appropriate, less wasteful, ways of living with things and that the current economic austerity therefore offers the potential for more sustainable forms of consumption to emerge (Evans, 2011). Reuse here is situated in discourses and practices of care. Holding on to, and caring about, possessions comes to stand for, 
or is regarded as, expressive of caring about a wider, temporally distant world of future generations. Exercising personal restraint in consumption in the present, through stewardship, is argued to have the effect of preserving future environments for distant generations - hence the connection to sustainable consumption. Reuse here, then, is a means to consume less and, as Evans (2011) argues, is located in frugality. Yet this sense of reuse works through slowing the circulation of things. As such, it fails to come within the orbit of waste policy, precisely because such goods remain within the household.

Scoping policy options for reuse in England therefore has focused on activities which would qualify as waste prevention but which move upstream towards the household from the hitherto primary focus of waste policy at the bottom of Fig. 1.

Moving to examine reuse means waste policy needs to engage with work in consumption studies, in which household practices are a primary concern. Studies of 'consumer culture' have identified the role of goods in the construction, performance and maintenance of social identities. People use possessions to signify and sustain senses of personal identity and status (Belk, 1988; Douglas and Isherwood, 1978; McCracken, 1988). The large body of work exploring these issues has addressed how the purchase of goods moves them across "value regimes". Research has traced how goods move from forms of "exchange value", that is articulated in terms of monetary price, to "use value", that is assessed in terms of utility to the possessor, but also emphasises that goods have "symbolic value". There are two key points about symbolic value which matter for thinking about reuse. First, goods function as status markers, indicating the affluence (or not) and taste of the owner; second, goods initially have symbolism attached to them through marketing and advertising but, as they are owned and possessed, their meanings shift to embody personal experience and history. An example would be the, say, designer jacket bought initially for its brand but which becomes valued instead as the garment worn during a significant life event. Consumption research shows how goods move across and between value regimes, gaining and losing monetary and/or symbolic value. It also shows how things move between being commodities (bought and sold for money) and gifts. An illustration is where parents pass on baby clothes they bought new but which have subsequently become invested with fond memories to those deemed worthy or socially significant others, as a way of respecting the meanings accrued in the garments (Clarke, 2000). All these studies suggest that the circulation of goods between and through households involves possibly multiple revaluations of what any particular item might mean.

A further area of work in consumption studies which matters for addressing reuse is the stocks of goods in households. The holding of stocks of goods, or surpluses, and their disposal also has symbolic value, as classic anthropological studies have shown, since the ability to give goods away, or to disregard monetary value, is also a marker of status. Households' stocks of goods may include a material surplus beyond immediate use that is held either 'in case' or for infrequent use, or for its symbolic worth, to indicate a modicum of wealth, of having more than enough. Some of these surplus stocks may be disposed of as waste (by placing them in the landfill or recycling bins) but others may be put back into circulation as either gifts or commodities, for example by giving them to friends and family, donating them to a school or church fete, putting unwanted clothes in a charity collection bag, or taking them to the charity shop, or posting them on eBay. It is these forms of 'exchange' relations, be they for money, as gifts or returns in-kind, which are captured within the policy umbrella term of reuse exchange.

The classic example used to exemplify reuse exchange within UK waste policy circles is furniture reuse networks, which collect unwanted, discarded household furniture, and then use voluntary labour to repair or recondition items to then be sold at low, or no, cost to those who cannot rely on standard market channels (Sharp and Luckin, 2006; Curran et al., 2007; Alexander and Smaje, 2008; Alexander et al., 2009). These have been the focus of UK policy attention due to their bulky and weighty character, which offers demonstrable diversion from landfill. Also included within the potential scope of reuse exchange is a heterogeneous array of activities including: car boot sales, charity shops, vintage shops, pawn shops and online auctions, and manufacturing, wholesale and retail activity involving reused products, for instance the recovery of goods derived from demolition (such as bricks and timber) and their subsequent reuse as construction products. Developing policy options for the promotion of reuse exchange has involved the comparison of this array of activities. This has entailed translating estimates of goods exchanged to estimates of the weight of goods exchanged, since for waste policy the imperative is to demonstrate the weight of goods (or materials) diverted from the waste stream by the various levels of the waste hierarchy. In turn, what counts for determining policy intervention is the demonstrable weightiness of that potential intervention. So, in comparing various options for enhancing reuse exchange it is the weight of goods estimated to be passing through various channels which will be critical to determining first whether policy intervention will occur, and second, which interventions are prioritised.

The paper reports on findings with respect to the weight of goods passing through 'car boot sales'. These are a British form of second-hand market combining features of a North American garage or yard sale and a European flea market. Sellers are generally householders but may be commercial traders who rent a pitch on, usually, an open field site that is licensed to function as a market on a prescribed number of specific days. A combination of survey work conducted in North East England and scale-up estimation shows such sites to be the means to the exchange of a significant weight of goods, broadly comparable with the weight of goods estimated to be flowing annually through the furniture reuse network. The paper then draws on parallel qualitative fieldwork, comparing this with previous research conducted on car boot sales in 1994/5 (Gregson and Crewe, 1997a, 1997b), to show that car boot sales are not motivated by waste prevention practices. ${ }^{1}$ Rather, they are strongly identifiable with the prevailing consumer culture of thrift (Miller, 1998; Evans, 2011). The paper therefore identifies a fundamental tension for policy intervention as it moves up the waste hierarchy and seeks to promote waste prevention through reuse. Reuse exchange may indeed be a means to incorporate certain activities (and the weight of goods passing through them) within the domain of waste policy and allow for demonstrating movement up the waste hierarchy. Furthermore, reuse may result from exchanges at car boot sales, but it is not the motivation for participation. What is, as we show, is more consumption, enabled by thrift. Whilst moving up the waste hierarchy is informed by notions of sustainable consumption and particularly the imperative to consume more frugally, activities that are labelled as reuse exchange are better understood as instances of prevailing consumer cultures rather than waste behaviours. The paper concludes by reflecting on this tension and its implications for UK waste policy.

\section{Methods}

Field surveys were conducted on three or more dates at each of six separate car boot sales in North East England over the period 3rd-27th May 2012 inclusive. The results were scaled-up to derive

\footnotetext{
${ }^{1}$ Although the opportunity for comparison with car boot sales in the mid 1990s is fortuitous, in that it is enabled by the changed policy context, the parallels between the recession of 2012 and that of the early-mid 1990s should be noted. Both pieces of research were conducted in periods of economic downturn.
} 


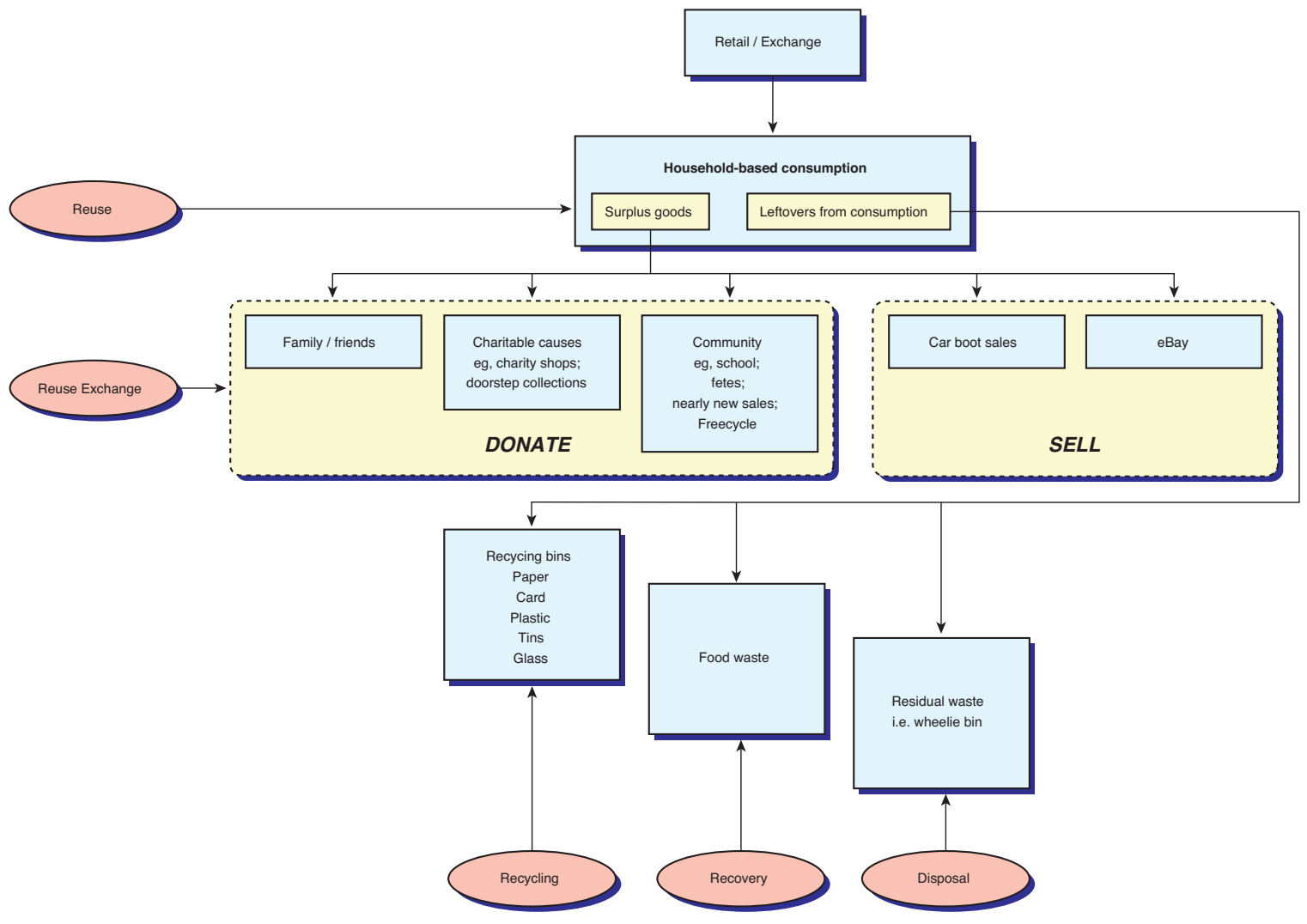

Fig. 1. Household consumption and the waste hierarchy.

estimates of the tonnage of goods exchanged through car boot sales in England.

The North East region was chosen as the basis for survey data collection to allow for comparison with previous research on car boot sales conducted during the mid 1990s. The six sites surveyed included five of the largest and most established car boot sales in the North East region, along with one newer, less established site. Each site was surveyed on three separate Sundays, often their only, and always their busiest, trading day; one site was surveyed on a further three occasions to cover the midweek trade occurring there, to generate a total of 21 separate sample points within the survey. Access was negotiated and agreed with operators and promoters, with surveys being conducted via spot interviews at the major exit points of sites by 13 field researchers. ${ }^{2}$ The sampling frame for each sample point varied according to people flow: at quiet times during a sale, at quiet sales, or at small sales, most people buying were surveyed; at large sales, and at times of high flow density through the exit gates, stratified sampling was deployed, with the aim being to survey approximately 1 individual/couple/family group in 10-20. A total of 2331 spot interviews with buyers were conducted across the 21 sample points. These spot interviews were standardised and focused exclusively on what had been purchased that day. A simple itemised record of purchases made by buyers was recorded along with a tally of those purchasing and not purchasing goods.

\footnotetext{
2 Notwithstanding access agreements, surveying at two of the six sites was conducted under conditions of bare toleration by site operators. Refusal rates for spot interviews were relatively high at the same two sites, whilst some of those who agreed to be surveyed openly reported only some of their purchases - 'I've bought such and such and such and such, but I'm not telling you what's in that bag'. It is possible therefore that the survey work under-reports the exchange of certain categories of goods.
}

Purchasing data were classified into 14 categories of household goods: white goods, electronics, clothing and accessories (including children's and baby), furniture, furnishings, kitchen and bathroom goods, media (books, CDs, DVDs, magazines), toys and baby/children-related goods (excluding clothing), garden and pet care, DIY goods, sports-related goods, car-related goods, miscellaneous, and new. These categories were chosen to be commensurate to those used in previous research on household disposal to enable comparisons (Gregson et al., 2007b). Goods recorded as purchased were retrospectively assigned estimated weights using a catalogue of weights derived from: a combination of the 2009 Furniture Reuse Network (FRN) weights data (http://www.frn.org); additional data produced through independent weighing of household goods, and product/manufacturer data gleaned from online retailer sites. ${ }^{3}$ FRN data provide a relatively accurate estimate of weights for furniture goods, garden, DIY and WEEE goods. However, this dataset is insufficiently differentiated for household goods, which comprise the majority of goods exchanged at car boot sales. Additional weights were assembled for all goods recorded using spring balance field measurements in households and product data from the websites of the following online UK retailers: John Lewis, MotherCare, Argos and Amazon. The average weight of purchase per surveyed buyer was calculated, firstly for sites, by category and by date and then across all sites. A final survey was conducted on 27th May 2012, recording estimated numbers of buyers and traders at 19 car boot sale sites identified as operational on that date in the North east region (Fig. 2$)^{4}$

\footnotetext{
3 Where a range of weights could be suggested for a recorded item, or where insufficient details about the size and substance of that item had been recorded by field researchers, an estimated average of highest and lowest weight was recorded. ${ }^{4}$ Identification of sites involved assembling local knowledge, cross checked against promoter advertising (online, local newspapers and free papers, leaflets and
} 


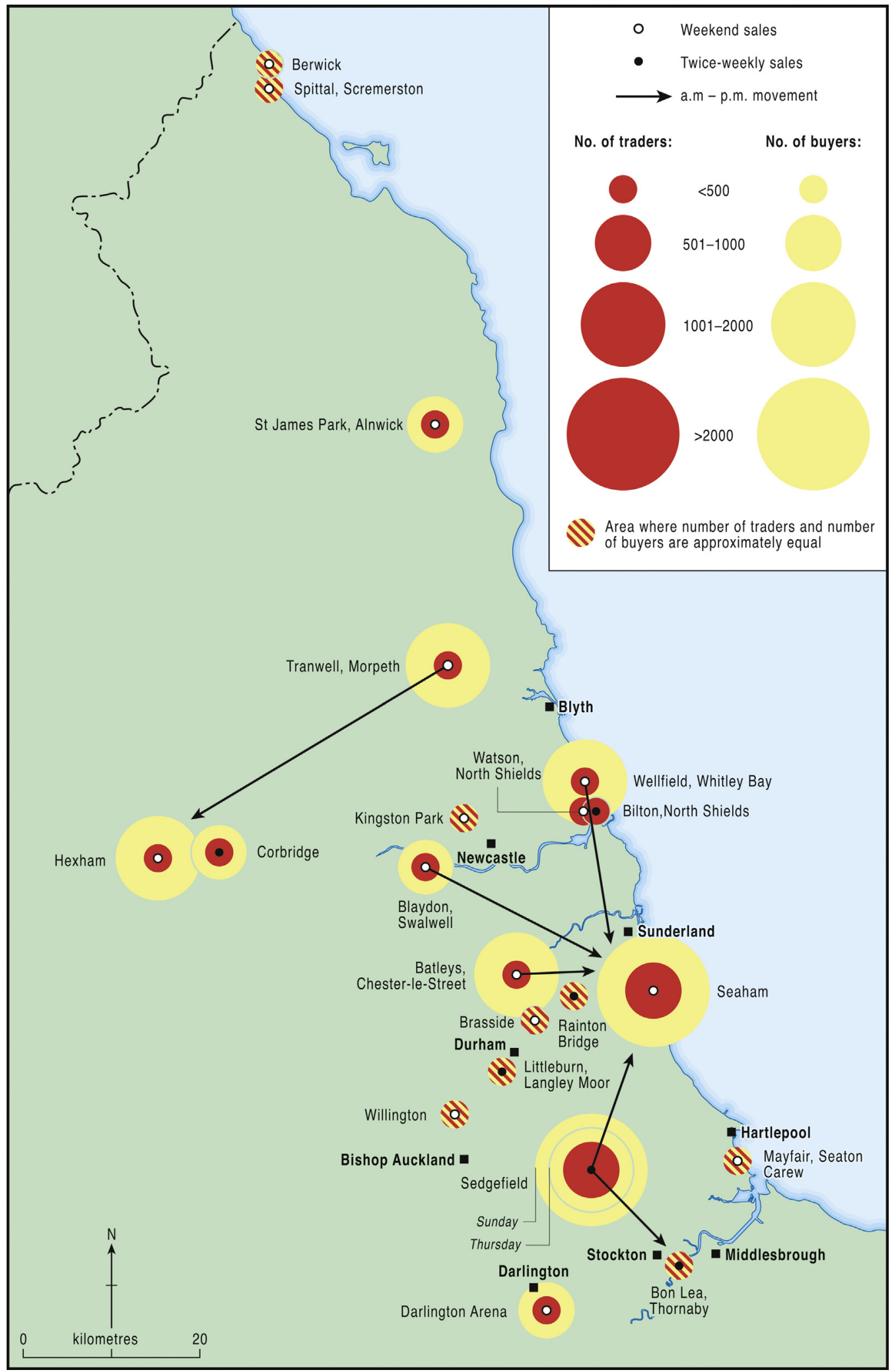

Fig. 2. Car boot sale activity: North East England, 27th May 2012.

casual road signing). The latter suggested that some 25 sites would be operational. However, a number of sales with an online presence turned out not to exist on the ground, with local people consulted showing no knowledge of any such sale or reporting that the sale had shut down some years previously. The inaccuracy of online databases of car boot sales is a familiar refrain amongst promoters, traders and buyers. Aside from communication issues, the primary reasons for the nonexistence of sales on the ground relate to either the commercial non-viability of a site or the failure of a promoter to secure planning permission for that site. 
Qualitative methodologies were deployed contemporaneously with the survey work, both to allow for greater interpretative depth and to enable comparison with previous research on car boot sales in the North East conducted over a 12-month period in the mid 1990s - some of which occurred at one of the sites surveyed in this research (Gregson and Crewe, 1997a, 1997b). Field researchers participated as buyers across all the surveyed sites; they traded at some of these sites, using goods sourced from their own households and from the pooled households of the field researchers and other colleagues; they engaged in casual conversation with buyers, traders and site operators; and they also interviewed promoters. Conversations here were non-standardised and focused more on why certain things were being purchased and by whom. Written field notes of observations were shared across the research team and assembled into a consolidated thematic document, which was then used to compare with the field notes from the previous research.

Estimates of the weight of goods exchanged annually at car boot sales in the North East region were extrapolated using the average weight of goods per surveyed buyer, assuming 28 trading weeks over the year for each of these 19 sites and the same volume of trade as indicated by the survey on 27th May 2012. Inevitably, there is a degree of uncertainty in these assumptions. Trade is not a constant (Fig. 3) and is sensitive to counter attractions and events; not all attendees actually buy (with the pattern of purchasing varying from 80 to $90 \%$ of people surveyed at five of the surveyed sites to 50 to $60 \%$ at the sixth); whilst the trade and footfall levels recorded at some of these sites on the 27th May 2012 survey were higher than previously recorded, by virtue of this being a hot "blue sky Sunday'. Nonetheless, 28 trading weeks is a reasonable average to assume, it being based on the prime car boot sale season of April-October inclusive. Within the April-October window certain sites will be restricted to trading on 14 separate occasions, that is, the maximum that is allowed without securing planning permission (Gregson et al., 1997). By contrast, a minority of the 19 sites, but which comprise the majority of surveyed trade, operate theoretically for a longer period than 28 weeks/year, because they have secured planning permission. However, there is one overwhelming influence on trade: the weather. The car boot sale business is 'subject to the vagaries of the English weather', as one promoter put this. Thus, whilst May 2012 saw a weekly pattern of average to strong trading across the majority of sites surveyed, June 2012 was widely declared to be 'a total wash out', with a majority of the 19 sites being waterlogged. The extrapolation used here underestimates the duration of trading over a year at certain sites but this is offset by using a day of buoyant trading as its baseline.

National scale estimates of the weight of goods being exchanged through car boot sales were extrapolated from the field survey data and North East population data. Inevitably, such exercises should be treated with caution, both on grounds of the localities used as the basis for the extrapolation and the methods, which must rely on proxies for participation. There is a fair degree of confidence that the North East is a reliable regional basis for estimation and that it is valid to extrapolate from regional participation estimates based on the North East population to the population of England as a whole, including London. Previous research on car boot sales, for example, suggested no structural variation in car boot sale occurrence across the English regions (Gregson et al., 1997). Other research on household provisioning through 'alternative consumption' sites has demonstrated no differences in the level and type of such provisioning between major UK cities (Leicester, Sheffield and Southampton) (Williams and Windebank, 2001; Williams and Paddock, 2003). Extrapolating from the field observations to a 28 week average season gives an estimated annual car boot sale footfall for the North East of 728000 . This figure is the equivalent of $28 \%$ of the regional population ( 2.6 million), although that is not to say that $28 \%$ of the North East's population attend
Table 1

Estimated annual weight of goods exchanged at car boot sales in the regions of England. Footfall and weight for NE region are based on 2012 fieldwork described in text. Those for other regions are estimates scaled according to population, assuming same relative footfall and weight per buyer. Population data are from ONS and for 2010. Population and footfall are rounded to three significant figures, weights to two significant figures.

\begin{tabular}{lccc}
\hline Region & Population (millions) & $\begin{array}{l}\text { Boot sale footfall } \\
\text { (millions/year) }\end{array}$ & $\begin{array}{l}\text { Boot sale weight } \\
\text { (tonne/year) }\end{array}$ \\
\hline NE & 2.61 & 0.73 & 3000 \\
NW & 6.94 & 1.94 & 7900 \\
Yks \& Humber & 5.30 & 1.48 & 6100 \\
E Mid & 4.48 & 1.25 & 5100 \\
W Mid & 5.46 & 1.52 & 6200 \\
E Anglia & 5.83 & 1.63 & 6700 \\
London & 7.83 & 2.19 & 9000 \\
SE & 8.52 & 2.38 & 9800 \\
SW & 5.27 & 1.47 & 6000 \\
England & 52.2 & 14.6 & 60000 \\
\hline
\end{tabular}

car boot sales. Nonetheless, research has shown that $22 \%$ of the UK population claimed to have visited a car boot sale in the previous 12 months (Williams and Paddock, 2003). Assuming the same footfall/population ratio of $28 \%$ of number of users found in the current survey to overall population as standard across all the English regions allows for the calculation of a national estimated car boot sale footfall. Estimated footfall can be used as a proxy for purchasing, although noting that purchasing patterns can vary between different sites. Multiplied by the average weight of purchase per surveyed buyer, the sum of national estimated footfall was used to derive an estimated annual tonnage of goods exchanged at car boot sales in England.

\section{Results}

\subsection{Field survey data and regional estimates}

The total estimated weight of goods purchased by those surveyed (over three weeks across six sites) was 9.5 tonnes. This corresponds to an average of $4.1 \mathrm{~kg} /$ buyer per visit (95\% confidence interval $\pm 0.6 \mathrm{~kg}$ ). The survey of $27 \mathrm{th}$ May 2012 recorded estimates of $\sim 2700$ traders and $\sim 20000$ buyers at the 19 operational car boot sale sites, giving an estimated 82 tonnes of goods exchanged $(20000 \times 4.1 \mathrm{~kg})$. Allowing for midweek trading at some sites, the tonnes of goods exchanged/week rises to an estimated 94 tonnes/week, and assuming 28 trading weeks gives an estimate of 2640 tonnes of goods exchanged annually through the North East's car boot sales.

\subsection{National estimates}

Assuming the footfall is around $28 \%$ of each region's population over the season gives a total annual estimated footfall of 14.6 million at car boot sales in England, which combined with the average estimated weight of purchases of $4.1 \mathrm{~kg} /$ purchaser yields a total annual estimated weight of 60000 tonnes being exchanged at car boot sales in England (Table 1). Allowing for observed purchasing patterns that $90 \%$ of attendees actually buy things yields an estimated tonnage of 54000 tonnes. Given the error margins, a ball park estimate is that $\sim 50-60000$ tonnes of goods are exchanged at car boot sales in England per annum.

\subsection{Patterns of purchasing}

Four categories of goods account for most of the purchasing activity at North East car boot sales (Table 2): toys and baby/children-related goods (excluding clothing) - 29\% of 


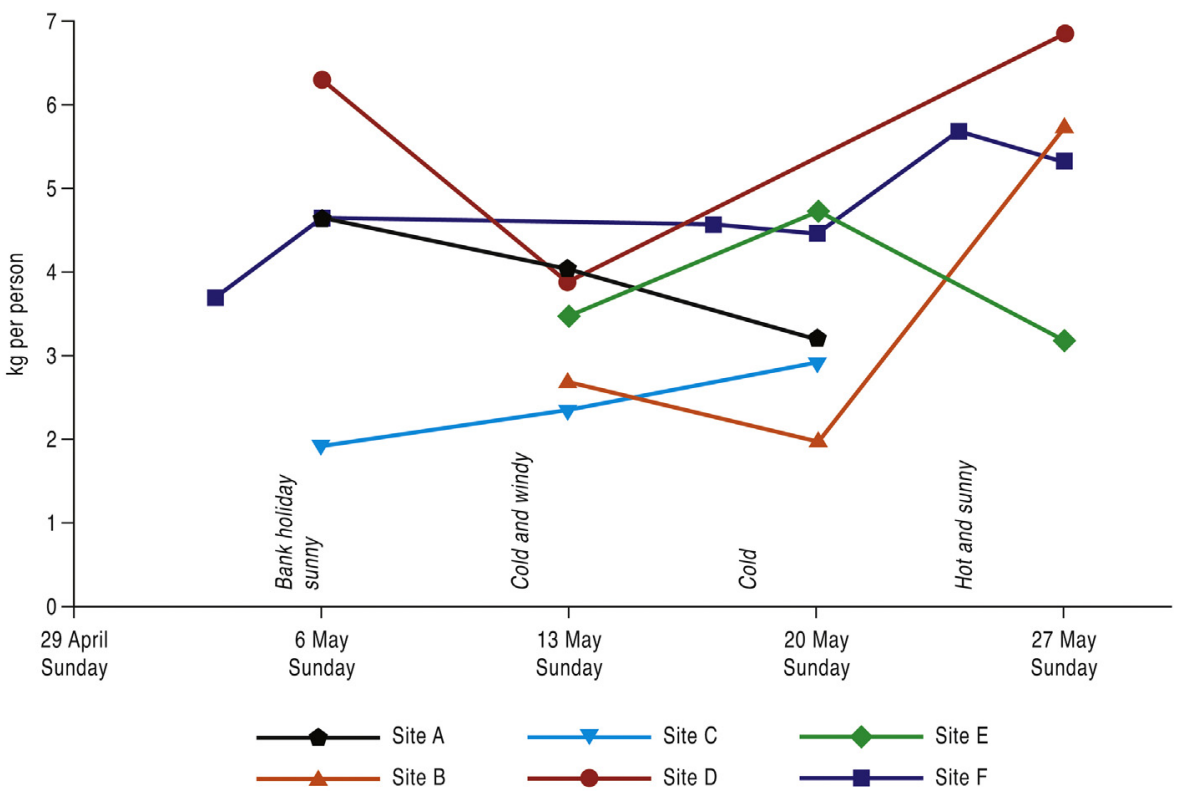

Fig. 3. Car boot sale trading: North East England, May 2012.

Table 2

Purchases by category and weight (across six surveyed sites).

\begin{tabular}{|c|c|c|c|c|c|c|c|c|c|c|c|c|c|}
\hline White goods & Electronics & Clothing & Furniture & Furnishings & Kitchen and bath & Media & Toys and baby & Garden and pet & DIY & Sports & Car & Misc. & New \\
\hline \multicolumn{14}{|c|}{ (a) Categories: (av. \% of surveyed buyers purchasing)a } \\
\hline 2 & 6 & 23 & 5 & 20 & 9 & 16 & 29 & 7 & 5 & 4 & 2 & 8 & 8 \\
\hline \multicolumn{14}{|c|}{ (b) Categories by weight (\% of mass of goods bought) } \\
\hline 4 & 4 & 5 & 14 & 11 & 5 & 5 & 23 & 10 & 4 & 7 & 2 & 6 & $\mathrm{n} / \mathrm{a}$ \\
\hline
\end{tabular}

a Numbers do not total $100 \%$ because buyers purchase in $>1$ category.

buyers surveyed had bought something/s in this category; clothing (23\%); furnishings (20\%) and media (16\%). The remaining categories typically figure in only $5 \%$ of buyers' purchases. This pattern of purchasing is consistent across all six sites surveyed (Table 3 ). In terms of estimated weights (Table 3), toys and baby/children-related goods account for $23 \%$ of the total weight of goods purchased. Other categories accounting for $>10 \%$ of the estimated weight of purchases are furniture (13\%) and furnishings (11\%). Toys and baby/children-related goods are by far the most important category of goods exchanged at North East car boot sales, both in terms of purchasing activity and by weight of goods. This category has grown very significantly compared with the mid-1990s data. Whilst clothing and media are significant categories of purchase, the low weight of individual items means that their contribution to the total estimated weight of goods exchanged is small.
However, the total weight of goods was not all connected with reuse. At one of the sites the purchase of basic new goods was also significant. Although not included in the weights data, new goods figured in $21 \%$ of surveyed buyers' purchases. New purchases at this site can be divided into five categories: food, household cleaning products, personal beauty and/or hygiene goods, kitchen goods and plants. Food purchased routinely over the survey period included biscuits and cakes, chocolate, tea bags, fruit, vegetables, multipack fizzy drinks and crisps, and multipack sausage rolls. The purchase of cleaning goods - particularly $2 \mathrm{~L}$ refills of cleaning fluid - figured prominently in spot interviews at this site, along with dish cloths, washing-up liquid and cleaning implements (mops, dusters). Personal beauty and/or hygiene goods - body sprays, perfumes, razors and tissues - were frequent purchases, as were tin foil, cling-film and annual garden plants. By contrast, another

Table 3

Patterns of purchasing.

\begin{tabular}{|c|c|c|c|c|c|c|c|c|c|c|c|c|c|c|}
\hline Site & White goods & Electronics & Clothing & Furniture & Furnishings & Kitchen and bath & Media & Toys and baby & Garden and pet & DIY & Sports & Car & Misc. & New \\
\hline \multicolumn{15}{|c|}{ (a) Purchasing by site - categories (av. \%: of buyers purchasing) } \\
\hline A & 2 & 5 & 22 & 4 & 19 & 9 & 18 & 32 & 5 & 6 & 5 & 2 & 3 & 21 \\
\hline B & 1 & 6 & 25 & 2 & 21 & 8 & 12 & 29 & 10 & 5 & 3 & 2 & 10 & 8 \\
\hline C & 2 & 4 & 22 & 3 & 15 & 11 & 24 & 31 & 2 & 4 & 3 & 1 & 8 & 6 \\
\hline $\mathrm{D}$ & 2 & 9 & 32 & 9 & 29 & 12 & 20 & 27 & 9 & 6 & 6 & 1 & 13 & 4 \\
\hline E & 1 & 5 & 21 & 4 & 18 & 9 & 19 & 30 & 5 & 4 & 4 & 1 & 5 & 0 \\
\hline $\mathrm{F}$ & 2 & 5 & 14 & 7 & 17 & 7 & 9 & 25 & 9 & 6 & 5 & 2 & 8 & 8 \\
\hline \multicolumn{15}{|c|}{ (b) Purchasing by site - \% estimated weight } \\
\hline A & 3 & 6 & 5 & 12 & 11 & 5 & 5 & 24 & 10 & 4 & 8 & 2 & 5 & - \\
\hline B & 6 & 3 & 6 & 4 & 10 & 4 & 4 & 31 & 12 & 5 & 8 & 3 & 4 & - \\
\hline C & 3 & 2 & 6 & 17 & 12 & 6 & 7 & 26 & 3 & 2 & 4 & 0 & 10 & - \\
\hline D & 9 & 4 & 6 & 22 & 13 & 3 & 5 & 12 & 10 & 2 & 7 & 1 & 6 & - \\
\hline E & 0 & 6 & 5 & 8 & 11 & 6 & 4 & 26 & 13 & 5 & 6 & 2 & 7 & - \\
\hline $\mathrm{F}$ & 2 & 3 & 3 & 19 & 9 & 5 & 2 & 19 & 11 & 6 & 6 & 8 & 7 & - \\
\hline
\end{tabular}


surveyed site regulates the sale of new goods closely. Whilst the sale of craft and/or handicraft goods is permitted along with the sale of household bedding plants, they do not allow the sale of new goods, seconds, clearance or discontinued lines, bankrupt stock and counterfeit or stolen goods. Food sales at this site are limited to ice cream vendors and burger vans and there are no traders selling cleaning products. Prohibiting the sale of new goods is the means by which this site differentiates itself from others in the region, with it being described by its organisers as a 'traditional' upmarket car boot sale, tacitly contrasted to 'commercial', downmarket others (Gregson and Crewe, 1997a). ${ }^{5}$

\section{Discussion}

The estimated weight of goods passing through car boot sales in England is two thirds that estimated to be diverted from the waste stream via the more well known and researched furniture reuse networks, or FRNs (90000 tonnes per annum http://www.frn.org). Given FRN data refers to the whole UK, rather than just England, this further supports that the weight of goods passing through FRNs and car boot sales are of a similar order of magnitude. Given the weight of furniture goods compared to the average weight of buyers' purchases at car boot sales, the volume of goods passing through car boot sales is undoubtedly far higher than that passing through FRNs. To estimate the number of goods exchanged, however, is difficult and next to impossible to achieve accurately since people are reluctant to unload carrier bags of purchases and instead will refer to goods purchased as 'a bag of books', 'a bag of toys', 'clothes' or even 'a bag of stuff. Purchasers do not think in terms of specific items on many occasions, particularly in relation to certain categories of goods (books, clothes, DVDs, toys). Nonetheless, car boot sales emerge from this research as enabling the exchange of a significant weight and volume of goods. Further, when combined with FRNs, charity shops and second-hand online sites, the research findings suggest that the category of reuse exchange is the means to capturing a considerable weight of activity within the orbit of waste prevention. Car boot sales therefore are sufficiently weighty sites for policy intervention that seeks to promote waste prevention. ${ }^{6}$ But what, if anything, do car boot sales have to do with waste prevention in the minds of participants? Does the mantra 'Reduce, Reuse, Recycle' mean anything in such sites? To answer these questions we turn firstly to the empirical findings from the field research and then, secondly, to position those findings more broadly within some of the work on consumption studies.

Discussions with both buyers and traders at car boot sales confirmed the continued veracity of the findings of previous research on car boot sales. For buyers, car boot sales are frequently 'a (family) day out'; they are valued for their sociality and sociability both in terms of the encounters they enable with unknown others (through goods) and for the way in which they offer something for everyone (c.f. Watson, 2009 on urban street markets). The array of goods on sale means that car boot sales are frequently used to buy

\footnotetext{
${ }^{5}$ As well as signalling the distinctions drawn between 'commercial' and 'traditional' car boot sales, this contrast also points to the connections between the local areas in which car boot sales occur and the quality of goods on sale (Gregson and Crewe, 2003). The site referred to here is located in an affluent market town. It contrasts markedly with two other surveyed sites, both of which are located near to areas identified as deprived on the basis of the multiple deprivation index (Durham County Council, 2010). Nevertheless, the key point about car boot sales is that they involve travel to sell and travel to shop. Buyers and sellers are not necessarily from the immediate local area in which a car boot sale is sited.

${ }^{6}$ It is salutary nonetheless to compare these estimates against the figures for household waste generation. The estimated weight of goods passing through car boot sales is of the order of $1 \mathrm{~kg} /$ person/annum, whereas the average household waste generated/household/annum is $431 \mathrm{~kg}$ (Defra, 2012).
}

\section{Box 1: The sociality of exchange Extract 1 - Site D (13.05.2012)}

All of the white vans and trailers are arranged around the outside of the field, interspersed with catering vans - hot dogs, drinks etc. As well as commercial traders there are House Clearance firms, one of which was a mine of amazing stuff. I nearly succumbed to buying two things from this stall. One was a light up globe in DayGlo Pink - serious discussion about 'did it work' or not - 'No idea - you could always just buy another fuse'. I decided to leave it. The other was a very kitsch John Wayne piece of bric-a-brac, which I went back to take another look at later. 'He' hadn't gone but he was very heavy, as well as slightly chipped, and by that time I was also carrying a copy of the Times World Atlas, which was the weight of the proverbial brick. So 'John Wayne' stayed on the table amidst Men's Incontinence Pads, a globe, random piles of bric-a-brac and something now dead which had once been alive:

A woman picks up a brown fur thing with a head and says: "What the $f^{* * *}$ 's that?! A ferret?" Male vendor (sitting in deck chair) raises eye brows and says: "Stuffed if I know - I think it's supposed to be a mink" [It looked to me more like a stoat]. Woman: "What $y^{\prime}$ er supposed to do with it then?" - laughs - "Wear it? Where?" She makes suggestive actions with the ferret/mink/stoat - much raucous laughter. The dead fur returns to the table next to 'John Wayne'.

\section{Extract 2 - Site E (27.05.2012)}

Vendors here sit about in their deck chairs sunning themselves, listening to the car radio and watching the world go by. Some attempt a more active sales pitch, like a woman who manages to sell a copy of A Thousand Stars to a passing woman by attaching the story to it: "It's a wonderful story - all about families, Afghanistan families so it's different to here; it's a really tragic story but a lovely story". She goes on about this until the woman relents and buys it - for 30p.

\section{Extract 3 - Site D (13.05.2012)}

NE woman in her 40s, inspecting baby carrier being sold by another woman, who is showing her its features, telling her "It's virtually brand new; here's its rain-cover; this goes like this" - she demonstrates. Potential buyer, inspecting it with her: "How much do you want for this then?" "15 quid." "Take a tenner?" "Oh go on then". Buyer: "I know what it's like I've done booties myself and by this time all you want to do is get shot of the stuff. This is for my 17 year old daughter. She's pregnant and I'm the one having to buy everything for her the whole lot".

'something for the bairn' [North East dialect for child], with large numbers of purchases involving treats of toys and/or clothing for children. At the same time, they are a means to acquiring almost any form of household goods, from the commonplace such as clothing, accessories and shoes, kitchen goods, bedding and soft furnishings, paperback books and DVDs, buggies, children's car seats and kids' bikes, through to the frankly obscure, such as church pews, brass hunting horns, rams' horns and gnomes. Amidst the sea of goods and 'just junk', there is always the potential for there to be something that catches the eye, or to which a story gets attached. That object may get bought, but equally sometimes its value is simply in the fun and sociality of the interaction that surrounds its discussion [Box 1]. At the same time, car boot sales are understood through the sense of getting a bargain, be that realised through haggling, "the find' or simply a price (20p, 50p or £2) that is much less than that on the high street or online second hand sites. Their appeal, for buyers, is that they both allow consumers to save money and to get more for their money. ${ }^{7}$

${ }^{7}$ A secondary line of appeal is in the connections between car boot sales and 'dodgy' traders and trading. These connections are repeatedly made in the media, 
Whilst some sellers are commercial or market traders, who find car boot sales attractive markets for remaindered goods, for perishable goods, and for goods whose provenance is unlikely to be challenged, for many traders car boot sales are a means to making money from no longer wanted household goods. There is a spectrum of participation here. Many begin trading by 'doing a booty' when they move house or when they feel the need for 'a good clear out'. For some, participation as traders remains at this level, that is, occasional. For others, however, there is the realisation that car boot sales are a means to making (small amounts of) money. In these instances 'the booty' becomes a habit or routine, something that is done on several occasions per year, and household goods become a form of 'stock', recognised as a source of potential monetary value as well as for their use. At the far end of the spectrum are those who trade most weeks during 'the season', for whom the extended family, friends and work colleagues become their supply chains. The range of non-commercial trader participation is illustrated in Box 2.

The spectrum of trader participation has its effects in the goods left unsold at the end of car boot sales - of which there are many. Very occasional traders will almost always adopt an 'everything must go' or 'give it away' strategy near the end of a sale, endeavouring to 'get shot of everything'. If they are left with unsold goods, and the site operates a strict 'no rubbish' policy, most will differentiate their goods into that which is to be 'taken to the charity shop' (in practice, any, or the one at which it is most convenient to drop stuff off) and that destined for 'the bin or the tip', thereby showing that car boot sales are a site in which goods can pass from value to waste, simply by virtue of not having found a buyer. By contrast, those for whom car boot sales are a habit will simply pack all the unsold stock away and bring it back to the next boot sale. The one exception to this pattern was the site situated in the area of highest socio-economic deprivation. Here vendors were not prohibited from leaving unwanted stuff behind, with the effect that this was scavenged over by humans and then birds, and eventually collected as part of the municipal waste collection service. ${ }^{8}$

Qualitative research reveals that there is very little connection in the minds of car boot sale participants between car boot sales and waste prevention activities. Explicit discussions framed through waste discourse occurred only when prompted by the purpose of the survey work, typically featured comments of the form 'Well, I suppose you could think of it like that, but...' and then referred to the allure of money saving and making, whilst also observing that goods being sold would not otherwise necessarily be discarded. They would also point to the difficulties of assuming reuse in relation to many car boot sale purchases, remarking that, from the perspective of buyers, quite a few things bought at a car boot sale would

and are reinforced by trading standards, the police and by promoters who exclude certain types of trade. A list of indicative regional and local media references appears at the end of the paper. For car boot sale participants, however, there is a sense that this is all 'part of the fun of the fair'. Car boot sales can be 'somewhere to go and get your holiday money - if you don't mind where it came from'. One of our surveyed sites was undoubtedly connected to the supply of soft drugs, whilst others clearly turned a blind eye to the sale of stolen and/or counterfeit goods. For many participants this kind of gossip and speculation is all part of the activity; spotting 'the dodgy stuff' is part of the day out (Gregson and Crewe, 1997a), whilst for others buying it is regarded as 'fair game', even if disclosing what it is - at least for a survey - was not. In this respect, the research confirms the findings of sociological work on how consumers relate to the illegal and illicit economy (Hobbs, 1998; Hornsby and Hobbs, 2007; Rutter and Bryce, 2008), whilst it is important to note the argument that eBay has transplanted the pub and the car boot sale as the primary means to selling counterfeit goods (Treadwell, 2012).

11 Data from site interviews with traders (27th May 2012).

8 A rapid survey of one pile of goods left behind on 6th May2012 revealed: a crate of cardboard boxes; a small bedside cabinet; a box of plates and other crockery; a CRT computer monitor; three board games; one CRT TV (small); a medium sized cabinet; two sets of shelving, and a vacuum cleaner.

\section{Box 2: Range of trader participation, excluding commer- cial traders ${ }^{11}$ \\ Regular, habitual traders at the site:}

Trader 1: Attended every week in the season (April - October). Interest started with a house clear out, and then developed into a pattern. 'It's quite a nice thing to do on a Sunday if the weather's nice'.

Trader 2: Attends every week and volunteers that they made £91 last week. They now collect stuff from neighbours and the extended family to sell, and also go around other car boot sales collecting stock.

Trader 3: Father \& daughter, of about 10-11. They sell every week. They don't have a car but live over the road so 'it's a handy way to make some money'. Father regards it as a way to give his daughter pocket money.

Trader 4: Prolific seller; used to sell here every other week (when it was on) and switch to another site when that was on. Has switched venues because she thinks she makes more profit at a smaller sale and it's less far to travel. Bigger sales provide too much competition; people haggle more. Started off selling her children's things and it had 'grown from there'. Now, like trader 2, she collects stuff from friends and family to sell. Has a concept of annual stock - what is left unsold at the end of the year goes to charity shops.

Trader 5: Regular trader, supplementing pension income to support the costs of running the car; saves anything unsold for potential resale.

\section{New to the site but a regular trader:}

Trader 6: Used to trade at another site but moved here 'because it's closer'.

\section{Irregular/occasional traders:}

Trader 7: Currently moving house and 'needing to get rid of a lot of clutter'. Also buys at car boot sales and then occasionally sells at other venues; plans to hold over unsold stuff from this sale for another sale at another venue the following week.

Trader 8: Moving to Australia; downsizing and planning to put remaining stuff into store.

soon end up in the bin anyway. The latter observation is indicative of the importance of the bargain at car boot sales (Gregson and Crewe, 1997a). What is being purchased is often the pleasure of the bargain per se, not the object to which the pleasure is temporarily attached. So, on returning home, the bargain can very quickly transform into junk and be chucked in the bin, precisely because it was so cheap to acquire. In other words, participants do not see car boot sales as related to waste prevention; nor do they see their purchases in waste prevention terms. Nonetheless, there are categories of goods where reuse undeniably does occur. Most notable here is the considerable amount of children's goods exchanged - be that clothing, toys, buggies, car seats, high chairs, bikes or cribs.

In contrast to buyers and traders, the effect of waste policy is more keenly felt in relation to the operation and promotion of car boot sale sites. The most obvious change in this respect relates to managing unsold and unwanted goods at the end of a sale. In $1994 / 5$, before the advent of any major waste diversion or reduction policy in England, such goods were abandoned on the site and 'the rubbish', as it was then called, was cleared up by site operators, at relatively low cost. In 2012, with the costs of disposal falling heavily on operators as the result of steep increases in the landfill tax, most opt to pass the transaction costs of waste management and disposal back onto traders. The context of waste minimisation is becoming apparent in the rhetoric of site operators and promoters with the beginnings of the adoption of the 'Reduce, Reuse, Recycle' mantra becoming visible. This can be seen in one logo for a car boot sale in the North East region, which states 'Don't Bin It, Sell It', whilst another online site promotes their car boot sales as 'a means to 
recycle and make money'. Other promoters, however, see 'Reduce, Reuse, Recycle' strategically as a means to promote the positives about car boot sales and, at the same time, of countering the long standing opposition to car boot sales from certain local authorities, for whom these informal sales are seen as a threat to their permanent markets (Gregson et al., 1997).

Qualitative research shows that, notwithstanding the gestures and nods towards waste policy by car boot sale operators, the sales themselves are steeped not in waste prevention but in the prevailing consumer culture: thrift (Miller, 1998). As Miller (1998) argues, shopping, be that on the high street, online, in a mall or a secondhand site, is the means by which people use acts of purchase to express their love and devotion to their significant others, usually their immediate families and particularly their children. This is what we see going on at car boot sales. For buyers, second-hand goods are a means to saving money but also of making that money go further to allow for more consumption. This is fundamentally a matter of thrift. Traders too show the link between car boot sales and thrift. However, unlike the case with second-hand shopping, second-hand trading is an entrepreneurial form of thrift. Encapsulated by the phrase 'I'd rather sell my stuff than give it away', it marks a transition in what is done with unwanted household goods, which began with the advent of car boot sales in the late 1980s and has carried on with the growth of online second-hand exchange sites, notably eBay (c.f. Lane et al., 2009). ${ }^{9}$ Whereas a range of second-hand sites (charity shops, freecycle, jumble sales and charity door step collections), depend on the donation of unwanted, surplus goods, effectively appealing to, and assuaging, consumer guilt through the act of donation, other second-hand outlets allow consumers to become petty capitalists. They allow consumers to reclaim the monetary value that remains in their goods, whilst passing on the use value to others through their exchange. Household possessions here revert to property or stocks: the right to their sale is a means both to potentially realising money and to not wasting money, by either giving away or throwing away goods. Selling at a car boot sale, then, like buying, is a means to saving money. It is a form of thrift. If there is waste being prevented it is by seeing disposal as a waste of money and seeking to recover the residual value in goods. Yet, as with buyers, the purpose is that it is a means to making household money go further. It is a means to more, not less, consumption.

Thrift matters for orienting car boot sales through waste prevention policies. Certainly, reuse in car boot sales is not a given, and at best is an effect of exchange rather than a motivating cause. But even more important is that it is doubtful that the goods that are offered for exchange in car boot sales are in the category of waste. Rather, they are surplus and transitional household goods. The surplus is a limbo land. Here, household goods are recognised to be no longer desired, wanted or needed by the household but at the same time they are goods which are not to be thrown away or discarded. They are not yet waste, but rather are stocks which have a recognised potential use and exchange value. Consequently, surplus goods are placed in conduits which seemingly allow such potential to be realised for the benefit of self or others - although equally those opportunities may be more apparent than real (Gregson et al., 2007b). In the UK, car boot sales are one such conduit; charity shops are another (Parsons, 2002; Horne and Maddrell, 2002; Hibbert et al., 2005), so too are FRNs, nearly new shops, the classifieds, and the plethora of second-hand sales of baby goods and clothes which characterise what Alison Clarke calls

\footnotetext{
${ }^{9}$ The vast majority of research on eBay is concerned with the dynamics of online auctions and trust. By comparison, a relatively small volume of work situates eBay within contemporary consumer cultures. See: Hillis et al. (2006), Denegri-Knott and Molesworth (2010), Laughley (2010), White (2010).
}

the moral economies of mothers (Clarke, 1998, 2000; Gregson and Crewe, 2003). ${ }^{10}$ To these we might add online sites such as freecycle and Gumtree which also rely on the donation of unwanted, surplus goods (Nelson et al., 2007).

The consistent message from the body of research on secondhand in consumption studies is that it is not reuse, in an environmental sense, which is valued about these sites but rather the possibility, belief even, that the circulation of surplus things through these sites not only does social good but is the right social thing to do. Donating surplus goods is both a moral and moralising act. As such it is an example of how consumer cultures work normatively. Selling the surplus, through a car boot sale for example, uses the market to realise that value for the self rather than others. Yet critically, either donating or selling the surplus connects to further acts of household expenditure which often work to reproduce the surplus. As the work of Miller, Gregson and Evans has shown, the presence of surplus goods in the household is central to understanding the morality of consumers. It both enables expressing love and devotion to significant others (the immediate family, and particularly children), through giving them choice (of what to eat, what to wear, what to play with and so on), and enables the release of goods to imagined, but always deserving, unknown others, thus connoting a sense of wider, social worth. At this point, we can see how thrift relates to the generation of the surplus: it is the means to ensuring the acquisition of a surplus. Frugality, by contrast, requires consumers to operate with little or no surplus. Frugality certainly reduces and prevents waste, and reduces consumption, but just how much sense of social worth can be construed through such a consumer culture is an open question.

\section{Conclusions}

In line with the imperative to develop options for reuse as part of waste prevention policy in England, a range of second-hand outlets have recently been appropriated within waste discourse through the category reuse exchange. This paper has demonstrated the weight of goods passing through one such form of secondhand outlet, car boot sales. It has shown this to be significant, of a similar order of magnitude to that passing through furniture reuse networks, and - by inference - to involve a far greater volume of goods. These sites therefore are important moments in the circulation and reuse of goods. At the same time, qualitative fieldwork conducted at car boot sales shows these sales to be located strongly within normative consumer cultures Thus, whilst they enable reuse, car boot sales are underpinned by the cultures and practices of thrift; for sellers, they are about realising value from stocks of goods, and for buyers they are about consuming more with less. They are a very long way from exemplifying the frugality which underpins notions of sustainable consumption.

Exposing the tension between thrift and frugality discloses a fundamental tension to be navigated by policy as it moves up the waste hierarchy. Interventions further down the hierarchy most notably in relation to household recycling - have attended to household discard (paper, metal cans, glass, plastic and card). These materials are the excess, or leftovers, of consumption. As such, for consumers they are both readily identifiable with waste and with environmental values, in the sense that doing the recycling can be identified with saving materials from landfill and recovering them as resources. Moving up the waste hierarchy brings waste

\footnotetext{
10 In a similar vein is a body of earlier research on garage sales (Freedman, 1976; Herrmann and Soiffer, 1984; Gordon, 1985; Parrish, 1986; Soiffer and Herrmann, 1987) and swap meets and flea markets (Maisel, 1976; Miller, 1981; Razzouk and
} Gourley, 1982; McCree, 1984; Belk et al., 1988; Sherry, 1990). 
policy into closer contact with consumer cultures. Practices of reuse exchange are not dealing with excess materials but rather with surplus goods. As we have shown in the paper, drawing on a body of work in consumption studies, surplus goods are socially and financially valuable. Their reuse and exchange are neither keyed in to environmental values nor to reducing consumption. Rather it is necessary to have a surplus stock of goods to enact key social identities such as that of being charitable, or being a good friend, or fostering ties between mothers through passing on and sharing goods. It is the sense of moral and social worth that these identities give rise to which motivates reuse exchange. Indeed, without surplus goods, one is placed either in the position of the recipient of others' charitable acts or firmly in the category of those too poor to give. The trouble for waste prevention policy, then, is that the social values that shape the reproduction of the surplus rely on more consumption and are quite the opposite of the environmental values that inform movement up the waste hierarchy.

The challenge for waste prevention policy in England is both to recognise and work from this collision of environmental and social values. What is being labelled as reuse exchange currently has very little to do with stewardship or environmental values. Rather what is valued here are the social and societal values that are produced through, or an effect of, the circulation of surplus goods. Rather than appropriating car boot sales and the like as a form of waste prevention, the policy goal of enhanced reuse may be achieved more easily through the converse tactic, that is, by accommodating reuse to align more easily with normative consumer cultures. One means by which this might potentially be achieved is by making it easier for consumers to release the surplus and easier for second-hand goods to circulate, through a variety of routes, be those located in the social economy or the market. There are many options relating to the promotion of online sites and charity collections and/or shops, but with respect to car boot sales, this might be achieved through allowing for an increase in the frequency of trade at particular sites through the relaxation of planning regulations, thereby giving more opportunities for sellers. A second means to achieving heightened levels of reuse through car boot sales would be to recognise that car boot sales, as with other second-hand outlets, result in traders with left over and unwanted goods which can all too easily enter the waste stream. If reuse is to be achieved through car boot sales, intervention needs to be targeted to capturing such goods for reuse as well as enabling consumers to do the right environmental thing more easily, through promoting the ease of circulation of the surplus.

\section{Acknowledgements}

Baseline estimation and scale-up research was funded by Defra. The research design and dissemination of research findings were approved by Defra. Opinions and interpretations are those of the authors only. The authors contributed to the paper as follows: NG (research design, fieldwork, data analysis, writing, preparation of figures and tables); MC (data analysis, writing); JL (survey work, fieldwork, field research management, data entry, commenting on manuscript); TF (survey work, fieldwork, field research management, data entry, commenting on manuscript); $\mathrm{HH}$ (scale-up estimation, commenting on manuscript). Thanks to the following Durham Geography Department post-graduate students for their field assistance: Nadia Al-Ghoweri, Gail Anderson, Stela Arar, Cat Button, Joanne Cairns, Jack Carter, Ladan Cockshut, Ankit Kumar, Ruth Machen, Jamil Mahmood, Wayne Medford, Matthew Perks, Nick Rush-Cooper and Jitu Thakur; to Chris Orton for cartographic work; and to Rob Ferguson and Colin McFarlane for comments on an early draft. Thanks to three referees for their helpful comments. The usual disclaimers apply.

\section{References}

Alexander C, Curran A, Smaje C, Williams I. An evaluation of bulky waste and furniture reuse schemes in England. Journal of Waste and Resources Management 2009;162:141-50.

Alexander C, Smaje C. Evaluating third sector reuse organisations in the UK: case studies and analysis of furniture reuse schemes. Resources, Conservation and Recycling 2008;52:719-30.

Belk R. Possessions and the extended self. Journal of Consumer Research 1988;15:139-68.

Belk R, Sherry J, Wallendorf M. A naturalistic enquiry into buyer and seller behaviour at a swap meet. Journal of Consumer Research 1988;14:449-70.

Clarke A. Mother swapping: the trafficking of nearly new children's wear. In: Jackson P, Lowe M, Miller D, Mort F, editors. Commercial cultures: economies, practices, spaces. Oxford: Berg; 2000. p. 85-100.

Clarke A. Window shopping at home: classified, catalogues and new consumer skills. In: Miller D, editor. Material cultures. London: UCL Press; 1998. p. 73-99.

Cooper T. Challenging the 'refuse revolution': war, waste and the rediscovery of recycling, 1900-50. Historical Research 2008;81:710-31.

Curran A, Williams I, Heaven S. Management of household bulky waste in England. Resources, Conservation and Recycling 2007;51:78-92.

Defra. Government review of waste policy in England 2011. Department for Environment Food and Rural Affairs; 2011.

Denegri-Knott J, Molesworth M. Love it. Buy it. Sell it. Consumer desire and the social drama of eBay. Journal of Consumer Culture 2010;10:56-79.

Defra. Local authority collected waste management statistics for England final annual results 2011-2012; 2012, Available at: https://www.gov.uk/ government/publications/local-authority-collected-waste-managementannual-results [last accessed 08.06.2013].

Douglas M, Isherwood B. The world of goods. London: Routledge; 1978.

Durham County Council. Index of Deprivation Report; 2010, Available at http://www.durham.gov.uk/Pages/Service.aspx?ServiceId=6013 [last accessed 08.06.2013].

Evans D. Beyond the throwaway society: ordinary domestic practice and a sociological approach to food waste. Sociology 2012;46:43-58.

Evans D. Thrifty, green or frugal: reflections on sustainable consumption in a changing economic climate. Geoforum 2011;42:550-7.

Freedman A. Garage sale folklore. New York Folklore 1976;2:167-76.

Gordon G. The trouble with garage sales. Journal of Consumer Research 1985; 14:449-70.

Gregson N, Crewe L, Longstaff B. Excluded spaces of regulation: car boot sales as an enterprise culture out of control? Environment and Planning A 1997;29:1717-37.

Gregson N, Crewe L. Performance and possession: rethinking the act of purchase in the light of the car boot sale. Journal of Material Culture 1997b;2 241-63.

Gregson N, Crewe L. The bargain, the knowledge and the spectacle: making sense of consumption in the space of the car boot sale. Environment and Planning D: Society and Space 1997a:15:87-112.

Gregson N, Crewe L. Second-hand cultures. Oxford: Berg; 2003.

Gregson N, Metcalfe A, Crewe L. Moving things along: the conduits and practices of divestment in consumption. Transactions Institute of British Geographers 2007b;32:187-200.

Gregson N, Metcalfe A, Crewe L. Identity, mobility and the throwaway society. Environment and Planning D: Society and Space 2007a;25:682-700.

Herrmann G, Soiffer S. For fun and profit: an analysis of the American garage sale. Urban Life 1984;12:397-421.

Hibbert S, Horne S, Tagg S. Charity retailers in competition for merchandise: examining how consumers dispose of used goods. Journal of Business Research 2005;58:819-28.

Hillis K, Petit M, Epsley NS, editors. Everyday eBay: culture, collecting and desire. London: Routledge; 2006.

Hobbs D. Going down the glocal: the local context of organised crime. The Howard Journal 1998;37:407-22.

Horne S, Maddrell A. Charity shops: retailing, consumption and society. London: Routledge; 2002.

Hornsby R, Hobbs D. A zone of ambiguity: the political economy of cigarette bootlegging. British Journal of Sociology 2007;47:551-71.

Lane R, Horne R, Bicknell J. Routes of reuse of second hand goods in Melbourne households. Australian Geographer 2009;40:151-68.

Lane R, Watson M. Stewardship of things: the radical potential of product stewardship for re-framing responsibilities and relationships to products and materials. Geoforum 2012 [online early].

Laughley D. User authority through mediated interaction: a case of eBay in use. Journal of Consumer Culture 2010;10:105-28.

Maisel R. The flea market as action scene. Urban Life 1976;24:488-505.

McCracken G. Culture and consumption. Indianapolis: Indiana University Press; 1988.

McCree C. Flea market. Psychology Today 1984;18:46-53.

Miller D. A theory of shopping. Cambridge: Polity; 1998.

Miller M. Patterns of exchange in the rural sector: flea markets along the highway. Journal of American Culture 1981;11:55-9.

Nelson MR, Rademacher MA, Paek HJ. Downdrifting consumer = upshifting citizen: an examination of a local freecycle community. Annals American Academy of Political and Social Science 2007;611:141-56. 
O'Brien M. A crisis of waste? Understanding the rubbish society. London: Routledge; 2008.

Parrish R. A garage sale is never as simple as you think: there's always something that stays to haunt you. Smithsonian 1986;17:133.

Parsons E. Charity retail: past, present and future. International Journal of Retail and Distribution Management 2002;30:586-94.

Razzouk N, Gourley D. Swap meets: profile of shoppers. Arizona Business 1982;29:8-12.

Rutter J, Bryce J. The consumption of counterfeit goods. 'Here be pirates?'. Sociology 2008;42:1146-64.

Sharp L, Luckin D. The community waste sector and waste services in the UK: current state and future prospects. Resources, Conservation and Recycling 2006;47:277-94

Sherry J. A sociocultural analysis of a Midwestern American flea market. Advances in Consumer Research 1990;17:13-30.

Soiffer S, Herrmann G. Visions of power: ideology and practice in the American garage sale. Sociological Review 1987;35:48-83.

Strasser S. Waste and want: a social history of trash. New York: Owl Books; 2000

Treadwell J. From the car boot to booting it up? eBay, online counterfeit crime and the transformation of the criminal marketplace. Criminology and Criminal Justice 2012;12:175-91

Watson $S$. The magic of the market place: sociality in a neglected public space. Urban Studies 2009;46:1577-91.

Williams C, Paddock C. Reconciling economic and cultural explanations for participation in alternative consumption spaces. Geografiska Annaler 2003;85B: 137-48.

Williams C, Windebank J. Acquiring goods and services in lower income populations: an evaluation of consumer behaviour and preferences. International Journal of Retail and Distribution Management 2001;29:16-24.

White M. What a Mess. eBay's narratives about personalization, heterosexuality and disordered homes. Journal of Consumer Culture 2010;10:80-104.

\section{Web references}

http://www.frn.org.uk/ [last accessed 16.07.2012].

http://www.thenorthernecho.co.uk/archive/2005/02/23/The+ North+East+Archive/6960666.Car_boot_sales_could_be_held_ responsible_for_illegal_goods/ [last accessed 09.06.2012].

http://www.thenorthernecho.co.uk/archive/2007/02/02/ Consett+\%26+Stanley+Advertiser+News+\%28neadvertiser_cas_ news\%29/1166085.Police_arrest_nine_people_in_raid_at_car_boot_ sale/ [last accessed 09.06.2012].

http://www.sunderlandecho.com/news/local/all-news/carboot-boss-turned-blind-eye-to-pirate-dvd-deals-1-1058055 [last accessed 09.06.2012].

http://www.sunderlandecho.com/news/local/all-news/ police-smash-major-counterfeit-ring-1-1116159 [last accessed 09.06.2012].

http://www.sunderlandecho.com/news/local/all-news/ car-boot-sale-criminal-convincted-1-1503367 [last accessed 09.06.2012].

http://www.sunderlandecho.com/news/local/all-news/comingsoon-to-a-car-boot-sale-near-you-1-1123370 [last accessed 09.06.2012]

http://www.hartlepoolmail.co.uk/news/local/12-01 pm-tradingstandards-warning-1-1037184 [last accessed 09.06.2012]. 